\title{
Working for psychiatric patients?
}

\author{
Mental health services and the White Paper
}

\section{EDWARD PeCK, Lecturer in Management, University of Newcastle and General Manager, Newcastle Health Unit, Newcastle upon Tyne NE3 8XT}

Working for Patients and the subsequent Working Papers mention psychiatric services explicitly only twice. The proposals have been formulated for patients requiring tests and treatment for elective surgical conditions. They are the conditions which are believed to be predictable and therefore the most receptive to contractual specification and pricing. The health care contract is to be central to the new NHS. It is the device by which the Department of Health hopes to produce a fundamental change in attitude by both doctors and managers. Kenneth Clarke seems much more concerned with this attitudinal shift than with the detail of what the NHS might resemble a decade from now. This omission of overt consideration of psychiatric services does not allow us to ignore the White Paper. I intend to focus on the potential implications of the proposed themes for psychiatric services, particularly in the context of what they might indicate about the Government response to Community Care: Agenda for Action.

The basis of health care contracts is the separation of service funding from service provision. The District Health Authority and participating GPs will become buyers. Private, self-governing and NHS non-trust hospitals will become suppliers. The connection between them is the contract for service. This division of purchaser and provider is familiar from the Griffiths Report on Community Care, "it is vital that social services authorities should see themselves as the arrangers and purchasers of care services - not as monopolistic providers". All hospitals will be financially dependent on the contracts they possess. In this respect there is no difference between a selfgoverning hospital and one which remains within the managerial auspices of the District Health Authority.

The criteria for hospitals becoming self-governing are laid out very broadly in the first working paper. This paper states that hospitals which have "adequate financial and management information systems" could opt to become self-governing. Recently, the Department of Health has been signalling that any hospital or unit could opt out as long as it fulfilled these vague criteria. This leaves the way open for mental health units to become self-governing. If relationships between psychiatric services and
District Health Authorities are to be conducted on a contractual basis, then there may be advantages to choosing self-government.

The first of these is that self-governing hospitals would attract the highest calibre of managerial and medical staff as they determine their own pay scales. Psychiatry has a bitter appreciation of the consequences of failing to attract and retain staff of sufficient competence and compassion. The second relates to the threat to the integrity of many mental health units of the prospect of acute hospitals taking their DGH mental health units with them into selfgovernment whether or not they are currently a managerial part of that hospital. Psychiatry does not have to look very far back to see the resource deprivation that was the result of having to compete with medical and surgical specialties. Furthermore, provision of acute psychiatric services being taken over by acute hospitals with the community care services being transferred to local authority control in the Government response to Community Care: Agenda for Action raises genuine worries about the continuity of care for psychiatric patients. Lastly, remaining DHA Units might all suffer financially in the face of the necessity of success of a local self-governing hospital.

To return to the contract, it is clear that the Department of Health intends that a paradigm which has been based on elective surgery can be made to embrace all forms of medical treatment. If the Government's timetable for change is to be adhered to, many of these contracts will at first be rough and ready but over time will pose new challenges in terms of defining quality and outcome of psychiatric services. Will the low predictive value of psychiatric diagnosis permit contracts for psychiatric services to be as detailed or prescriptive as those for hiatus hernia repair? Nonetheless, as resource management is based upon accurate medical diagnosis, introduction of resource management projects into psychiatric services would serve to re-emphasise the primacy of the medical model.

Working for Patients and the subsequent papers assume that patient care is the province of doctors. Reading them gives no evidence that other professions are involved in looking after patients. 
Working Paper 7 declares that doctors "are the leaders of clinical teams, responsible for all aspects of clinical care for the patients under their charge". This may reassure consultant psychiatrists troubled by the assertiveness of non-medical colleagues but completely overlooks the complexity of multidisciplinary working in mental health teams. In terms of the White Paper, this could produce at least two problems. The first is the method by which psychiatrists will introduce medical audit - "the systematic critical analysis of the quality of medical care and the resulting outcome and quality of life for the patient" (Working Paper 5) - while addressing factors which Working Paper 6 recognises apply to audit in general practice, e.g. team working, environmental factors etc. The second relates to the clear implication that improved service management relies on the ability of "consultants and managers to work together" (Working Paper 7) which could clearly undermine the progress made in interdisciplinary and interagency management since 1975 .

While maintaining the status of doctors within the proposals, Kenneth Clarke has been consistent and deliberate in his exclusion of them from the formulation of the White Paper. The Department of Health has indicated that the detail might be open to negotiation but that the essential reforms outlined in the eight working papers are not. Excluded from the production of the proposals and labelled by Mr Clarke as a self-interested trade union, the BMA is fighting for its political credibility both with the Department and its members. As the BMJ (Macpherson, 1989) observed, "the fate of this White Paper could tell as much of the skills of public relations experts as the arguments of medical experts... The profession must formulate its views, remain united and be prepared for a tough campaign". If the Government does succeed in resisting medical opposition to the White Paper proposals it would appear unlikely that professional interest groups will have much success undermining those aspects of the response to Griffiths that they find unpalatable. The right of such groups to be involved in policy formulation and the need for professional consensus around proposals are under threat. The NHS is currently experiencing a level of instability rare even for this most reorganised of welfare services. It is hard not to conclude that the creation of such instability is a deliberate Government tactic based on the premise that out of the instability will arise change. It appears we have no option but to accept the new contractual paradigm. The challenge for psychiatric services is to seize upon those aspects of the White Paper which might be of benefit to psychiatric patients and to implement change. With this in mind, I would like to return to the division of service purchaser from service provider.

Sir Roy Griffiths in his report on Community Care suggested the extension of case management. The key tasks of case management are "providing case managers with the opportunity, control over a budget, consensus and knowledge to mobilise resources to achieve more equitable and efficient outcomes for clients and carers" (Challis \& Davies, 1986). This approach to case management envisages the professional co-ordinating a package of care for an individual which may involve contracting for services from the agency for which the professional may work and certainly means that the professional provides some aspects of that care himself. The separation of buyer and provider is not clear.

If psychiatric services wish to pursue this then they need to consider a system developed in Canada called Service Brokerage. Detailed descriptions of the system are now being published in this country (e.g. Brandon \& Towe) but broadly it is based on the model of an independent case manager who assesses, and a service broker who then purchases, the required package of care from a range of service providers. These providers only continue to receive funding if that service broker, the case manager, and crucially, the disabled individual, remain satisfied with the quality and quantity of service received. A Mental Health Unit which piloted such an arrangement, for instance using dowry payments which attach to individual patients returning from long-stay hospitals, might well make the introduction of contractual distance between purchaser and provider genuinely work for psychiatric patients.

\section{References}

Brandon, D. \& TowE, N. (1989) Free to Choose. London: Good Impressions.

Challis, B. \& Davies, B. (1986) Case Management in Community Care. London: Gower.

Department of Health (1989) Working for Patients. London: HMSO.

(1989) Working Papers 1-8. London: HMSO.

GrIfriths, R. (1986) Community Care: An Agenda for Action. London: HMSO.

MACPHERSON, G. (1989) BMA's measured response. British Medical Journal, 298, 340-341. 